\title{
Alumina-based nanoparticles obtained by anodic dissolution of Al in electrolytes with alcohol solvents
}

\author{
Maria Starowicz • Pawel Starowicz • Barbara Stypula
}

Received: 3 December 2013 /Revised: 4 February 2014 / Accepted: 1 March 2014 / Published online: 18 March 2014

(C) The Author(s) 2014. This article is published with open access at Springerlink.com

\begin{abstract}
In the present work, alumina-based nanoparticles were produced by an electrochemical method. Alcohols (methanol, ethanol, and propanol) containing $5 \%$ of water and $\mathrm{LiCl}$ were applied as electrolytes. Sizes of the micelles in the obtained solution ranged from $200 \mathrm{~nm}$ to over $1 \mu \mathrm{m}$ depending on the used alcohol. Measurements performed by ultraviolet and visible light (UV-VIS) spectroscopy indicated a presence of aluminum oxides and hydroxides in the solution. Studies using transmission electron microscopy (TEM) revealed that the obtained nanoparticles are in a form of flakes and membranes and their size is $\sim 200 \mathrm{~nm}$ for methanol and $\sim 50 \mathrm{~nm}$ for propanol. The composition of the product was characterized by the Fourier transform infrared spectroscopy (FTIR) and x-ray diffraction (XRD). It consists of amorphous $\mathrm{Al}$ oxides and hydroxides as well as poorly crystallized aluminates and metallic Al.
\end{abstract}

Keywords Aluminum oxides · Electrochemical synthesis · Alcohol solution $\cdot$ Nanoparticles

\section{Introduction}

Nanoparticles of aluminum compounds are of particular importance due to their properties, which are different from those of a bulk material. The first examples of numerous applications include energetics, where $\mathrm{Al}_{2} \mathrm{O}_{3}$ nanoparticles are used

\footnotetext{
M. Starowicz $(\square) \cdot$ B. Stypuła

Faculty of Foundry Engineering Department of Chemistry and Corrosion of Metals, AGH University of Science and Technology, Reymonta 23, 30-059 Krakow, Poland

e-mail: mariast@agh.edu.pl

P. Starowicz

M. Smoluchowski Institute of Physics, Jagiellonian University, Reymonta 4, 30-059 Krakow, Poland
}

[1] and a catalysis employing boehmite $(\mathrm{AlOOH})$. The catalytic effect of colloidal AlOOH nanoparticles influences the kinetics of the oxidation of iodide by persulfate [2]. Moreover, $\mathrm{AlOOH}$ nanoparticles have absorptive properties and because of this are applied in nanocomposites. The biochar/AlOOH nanocomposite can be used as a multifunctional and highly effective adsorbent to remove aqueous contaminates, such as organic and inorganic pollutants from wastewater [3]. The lamellar $\gamma$-AlOOH architectures may be applied as potential adsorbents for $\mathrm{HCN}$ in toxic pollutant solutions and cigarette smoke [4]. The next example is AlOOH boehmite in a form of nanorods, which is used as filler for sol-gel and polymerbased composite coatings, which improves the fracture toughness [5]. The nanostructured $\mathrm{Al}_{2} \mathrm{O}_{3}-\mathrm{Ni}$ composite coatings have a better corrosion resistance than pure nickel coating [6]. $\mathrm{Al}_{2} \mathrm{O}_{3}$ and $\mathrm{LiAlO}_{2}$ nanoparticles are used to cover a cathode in lithium ion batteries in order to improve cathodic electrochemical properties [7]. Finally, the $\mathrm{Al}_{2} \mathrm{O}_{3}$ nanoparticles play the role of a solid plasticizer for a polymer matrix, which also ameliorates the properties of the lithium ion batteries [8].

Such a broad area of applications stimulated the development of various methods employed to produce $\mathrm{Al}$ oxide nanoparticles. Typically, these are hydrothermal methods $[4$, $9,10]$. Hou et al. [4] synthesized lamellar $\gamma-\mathrm{AlOOH}$ architectures via a hydrothermal route. Different product structures were obtained by varying the molar ratio of aluminum nitrate and cetyl trimethyl ammonium bromide (CTAB) [4]. To synthesize $\gamma$-AlOOH nanorods, $\mathrm{AlCl}_{3}$ and $\mathrm{NH}_{4} \mathrm{OH}$ were used as reactants and $\mathrm{H}_{2} \mathrm{SO}_{4}$ played the role of a morphologydirecting agent [9]. Tang et al. has also successfully synthesized $\gamma$-AlOOH hollow spheres with nanoflake-like porous surface texture in course of an ionic liquid-assisted hydrothermal synthesis in citric acid monohydrate [10].

There are also other methods which are alternative to the hydrothermal synthesis. For example, Zheng's group has produced $\gamma-\mathrm{AlOOH}$ and $\gamma-\mathrm{Al}_{2} \mathrm{O}_{3}$ materials with various shapes 
by modulating the amount of ionic liquid in the reaction system [11]. Boehmite $(\mathrm{AlOOH})$ with flower-like structures was obtained by the solvothermal reaction of $\mathrm{AlCl}_{3}-6 \mathrm{H}_{2} \mathrm{O}$ in the presence of ethanol and toluene at $200{ }^{\circ} \mathrm{C}$ [12]. Spherical boehmite $(\mathrm{AlOOH})$ particles were synthesized from aluminum sulfate and aluminum chloride solution with urea as precipitant at $90^{\circ} \mathrm{C}[13] \cdot \gamma$-AlOOH architectures with hollow and self-encapsulated structures have been obtained by a onestep wet-chemical route [14].

Electrochemical synthesis of various metal oxide nanoparticles has been proposed for different metals so far [15-18]. On the other hand, a production of nanoparticles based on aluminum anodic polarization is rather an unexplored subject. Therefore, the main objective of the study was to use the process of aluminum anodic dissolution to produce nanoparticles of aluminum compounds.

\section{Experimental}

Electrochemical studies of aluminum were carried out in LiCl-ethanol solution with a three-electrode system, which was composed of a platinum auxiliary electrode, an $\mathrm{Ag} / \mathrm{AgCl}$ reference electrode, and an $\mathrm{Al}$ working electrode. Galvanostatic synthesis of aluminum compounds was performed in $0.05 \mathrm{M} \mathrm{LiCl}-$ methanol, ethanol and propanol solution containing $5 \%$ (vol.) of water. Electrolytic cell with five-electrode system was used to synthesize nanoparticles. Three Al plates with the dimensions of $100 \mathrm{~mm} \times 10 \mathrm{~mm} \times 0.2 \mathrm{~mm}$ and parallel orientation were used as anodes. Two cathodes made of $\mathrm{Al}$ wire with 3-mm diameter were located between the anodes. The distance between anodes and cathodes was $15 \mathrm{~mm}$ in each case. Argon gas was flowing through the solution from two opposite sides of a cylindrical vessel, in order to maintain oxygen-free atmosphere and assure constant mixing of the solution. Current density equaled to $3 \mathrm{~mA} / \mathrm{cm}^{2}$ for all the solutions. The polarization potential, with respect to an $\mathrm{Ag} /$ $\mathrm{AgCl}$ reference electrode, amounted to $0.4,2.6$, and $4.7 \mathrm{~V}$ for methanol, ethanol, and propanol solutions, respectively. The main criterion for choosing the potential was a similar efficiency of the nanoparticle synthesis, what was reflected by the same current densities of $3 \mathrm{~mA} / \mathrm{cm}^{2}$. Duration of the polarization process amounted to $3 \mathrm{~h}$ in each case. The synthesis was carried out at room temperature. Following the polarization, structure, and properties of the colloidal solution containing nanoparticles were investigated by means of ultraviolet and visible light spectroscopy (UV-VIS) with Lambda 25 PerkinElmer instrument, fourier transform infrared spectroscopy (FTIR) with Thermo Scientific Nicolet 6700 spectroscope and a Zetasizer Nano ZS nanosizer from Malvern company. The dried deposit was studied by FTIR, transmission electron microscopy with Tecnai FEG SuperTwin
$(200 \mathrm{kV})$ instrument, and x-ray diffraction using PANalytical Empyrean diffractometer with $\mathrm{Cu} \mathrm{K}_{\alpha}$ radiation.

\section{Result and discussion}

The curves of aluminum polarization in ethanol solutions with the concentration between $0.001-\mathrm{M} \mathrm{LiCl}$ and $0.1-\mathrm{M} \mathrm{LiCl}$ are presented in Fig. 1. The shape of the curves is characterized with two slopes. It is known that aluminum dissolution is realized in a two-step process in the case of anhydrous alcohol solutions with chlorides [19]:

$\mathrm{Al} \leftrightarrow \mathrm{Al}_{\mathrm{ad}}^{+}+e^{-}$

$\mathrm{Al}_{\mathrm{ad}}^{+} \leftrightarrow \mathrm{Al}^{3+}+2 e^{-}$

The flat $i(E)$ dependence at low anodic potential (Fig. 1) is generally related to a chemisorption of solvent and electrolyte as well as to a formation of an intermediate product. At the low potential, an unstable anodic layer is also formed, which inhibits metal dissolution. The intermediate products of oxidation containing a metal with lower oxidation level are more stable in organic environments when compared to hydrous solutions [19]. When a higher anodic potential is reached (approximately $E>-1.0 \mathrm{~V}$ ) the metal surface is activated and undergoes significant structural etching [19]. $\mathrm{Al}^{3+}$ ions, as a product of oxidation, are transferred to the solution in a form of soluble complexes. This second potential range is characterized by a rapid increase of current (Fig. 1). It is noteworthy that the transition from the passive to transpassive range (or a desorption potential) is shifted to lower potential with the increase of $\mathrm{LiCl}$ concentration. The attempts to synthesize

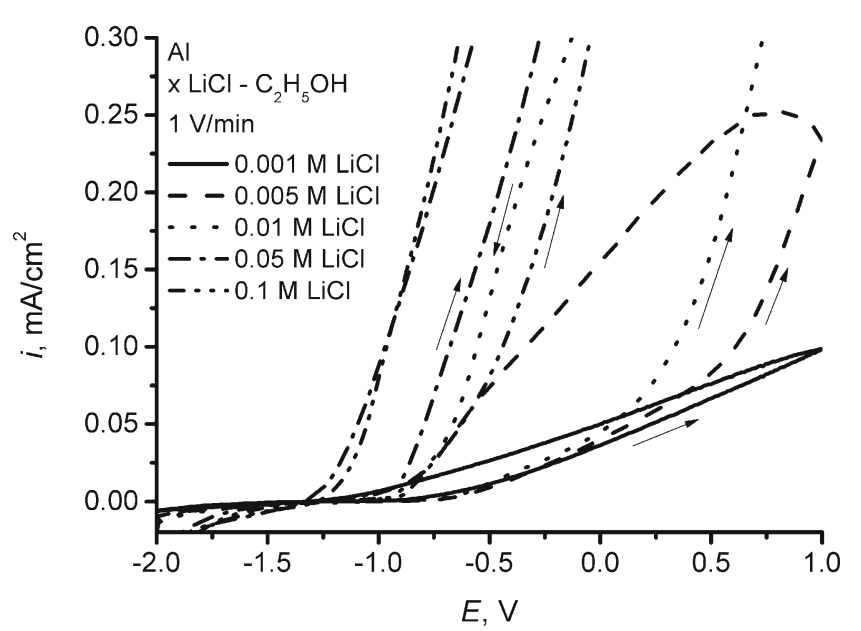

Fig. 1 Polarization curves for aluminum in ethanol solutions as a function of $\mathrm{Cl}^{-}$ion concentration 


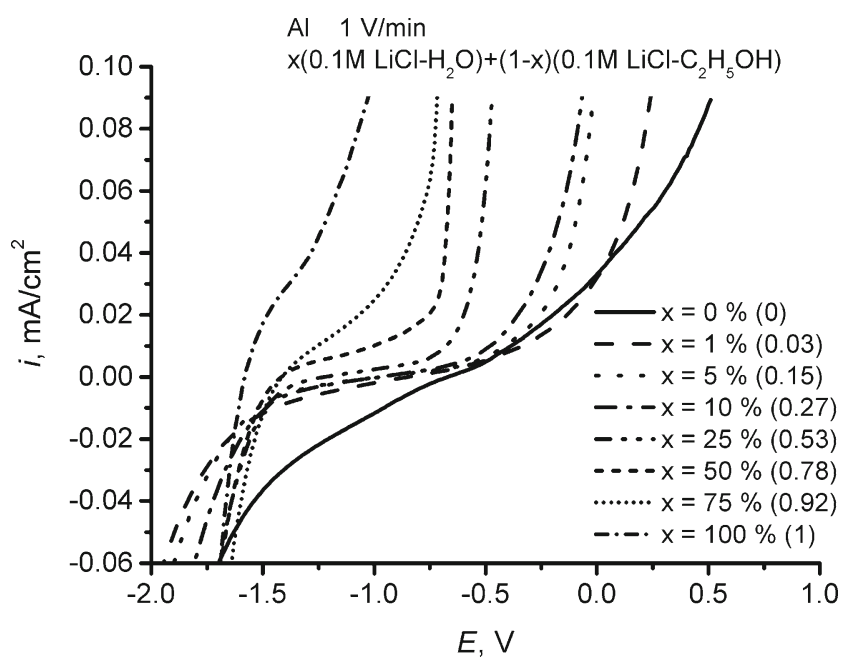

Fig. 2 Anodic curves from the cyclic voltammetry studies of aluminum in $x\left(0.1 \mathrm{M} \mathrm{LiCl}-\mathrm{H}_{2} \mathrm{O}\right)+(1-x)\left(0.1 \mathrm{M} \mathrm{LiCl}-\mathrm{C}_{2} \mathrm{H}_{5} \mathrm{OH}\right)$ solution. Molar ratio is given in brackets

nanoparticles were made for the second transpassive range. Initial studies revealed that already for the anodic potential of $-0.1 \mathrm{~V}$ in $0.05 \mathrm{M} \mathrm{LiCl-ethanol} \mathrm{solution} \mathrm{a} \mathrm{suspension} \mathrm{is}$ formed. However, the electrochemical processes related to a formation of nanoparticles are expected also for higher potential in the transpassive range. Therefore, as specified in the precedent paragraph, higher potentials were chosen, which resulted in the highly efficient synthesis of nanoparticles.

The addition of water to the solution influences the kinetics of anodic oxidation, similarly to other metals [17]. The influence of water concentration on the course of the anodic process is presented in Fig. 2. The presence of water in alcohol causes a passivation of aluminum surface in analogy to the cases of iron and other metals [17]. The increase of water content shifts desorption potentials to lower values and gives rise to the increase of current density in the dissolution range. Values of

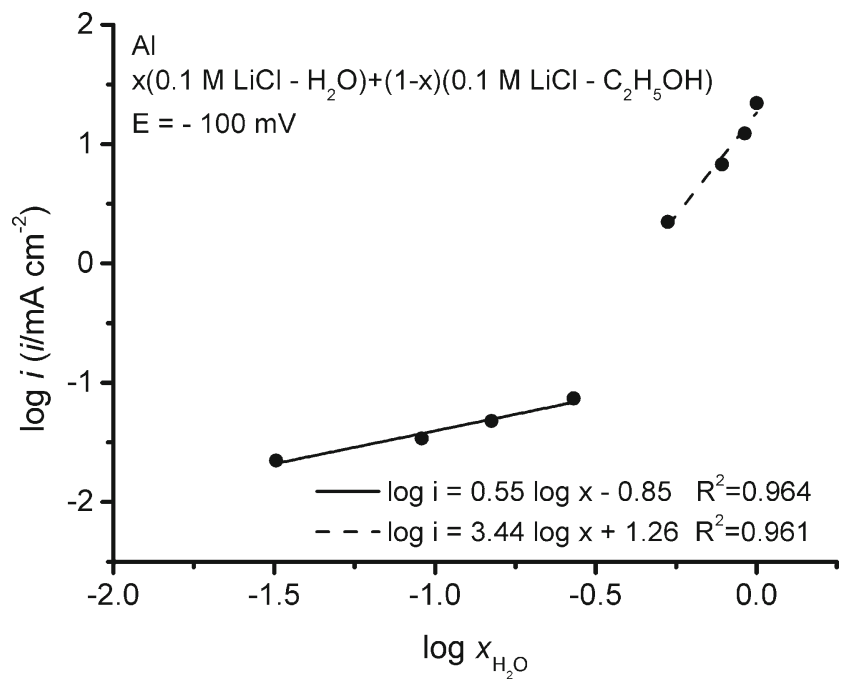

Fig. 3 Reaction order determined with respect to water concentration, where $x_{\mathrm{H}_{2} \mathrm{O}}$ is expressed in molar ratio

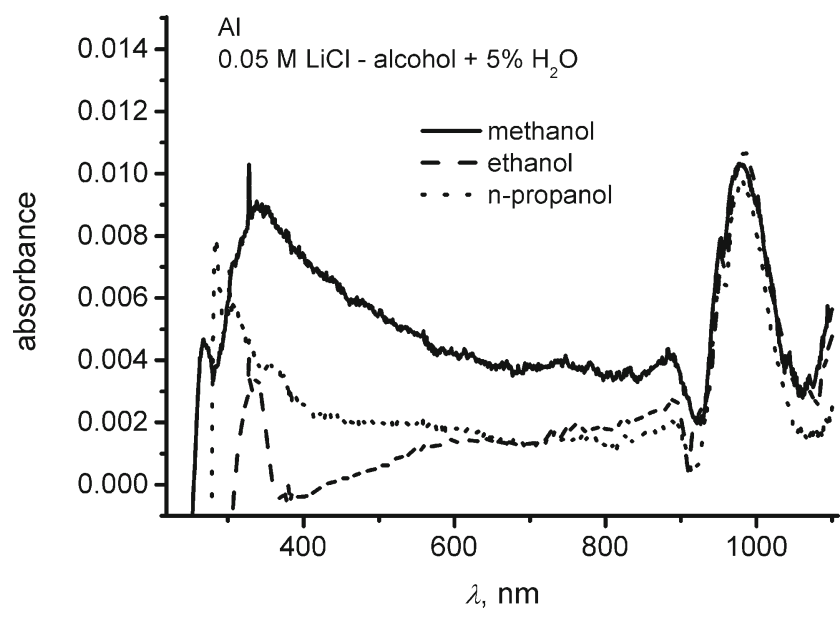

Fig. 4 UV-VIS studies of the colloidal product obtained by the galvanostatic polarization of aluminum in the $0.05-\mathrm{M} \mathrm{LiCl}-$ alcohol $+5 \% \mathrm{H}_{2} \mathrm{O}$ solutions

the reaction order with respect to water concentration (Fig. 3) were determined from the anodic current density at the constant potential in the intensive etching range $(E=-100 \mathrm{mV})$. Two values of the reaction order indicate the existence of different mechanisms of the process. The reaction order is fractional and amounts to 0.5 at low water concentration; below 0.53 molar ratio $(x=25 \% \mathrm{vol})$. It equals to 3.44 for the concentrations higher than 0.53 molar ratio. Such a behavior is determined by a change of alcohol-water- $\mathrm{LiCl}$ solution structure. The change of water concentration affects acid-base properties of alcohol solutions and influences the secondary processes. Colloidal solutions and/or microparticle suspensions are formed as an effect of hydrolysis, which is a secondary process.

The colloidal solutions, being the product of the galvanostatic polarization, were subjected to various studies in order to determine the chemical composition and morphology. The

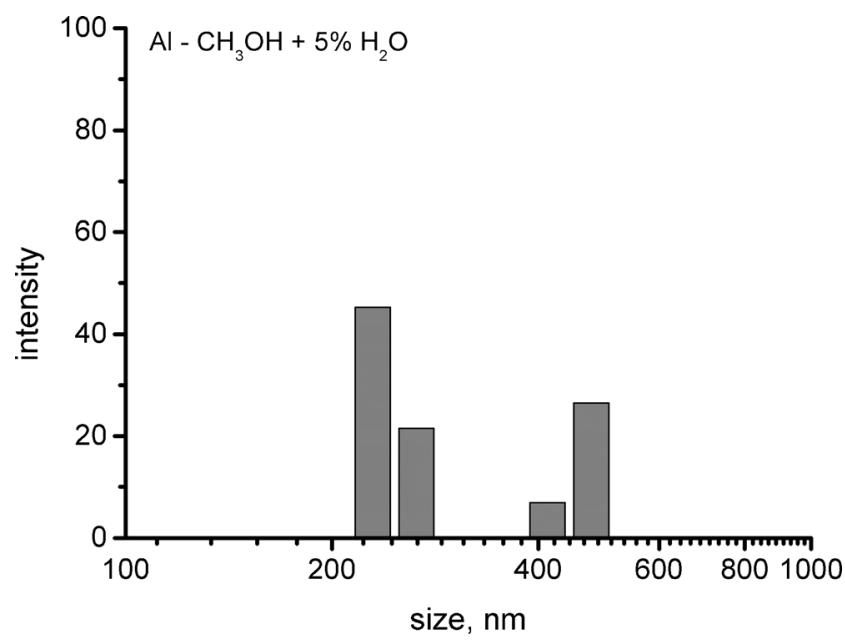

Fig. 5 Distribution of micelle size in the colloid obtained by a galvanostatic aluminum polarization in the $0.05-\mathrm{M} \mathrm{LiCl}-\mathrm{CH}_{3} \mathrm{OH}+5 \% \mathrm{H}_{2} \mathrm{O}$ solution. Data were collected by the nanosizer 


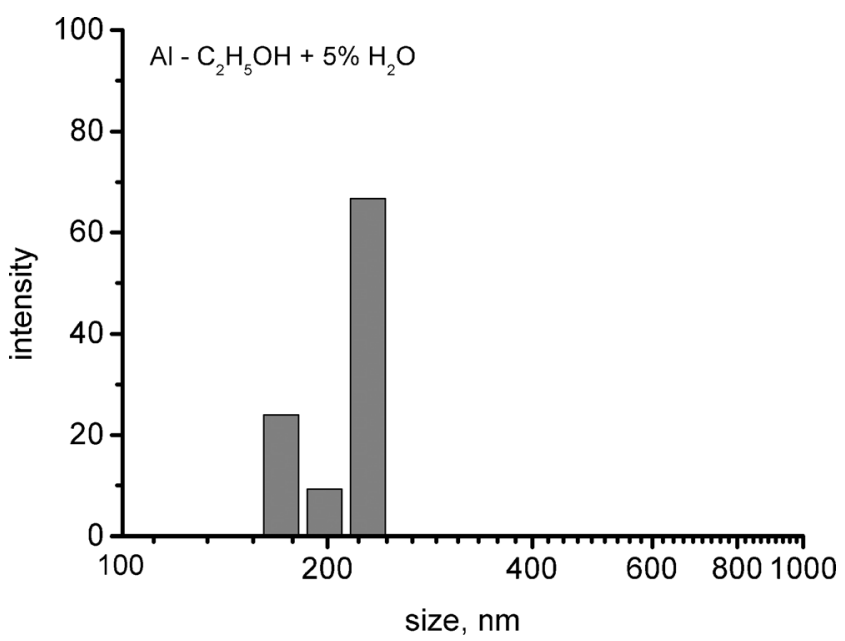

Fig. 6 Distribution of micelle size in the colloid obtained by a galvanostatic aluminum polarization in the $0.05-\mathrm{M} \mathrm{LiCl}-\mathrm{C}_{2} \mathrm{H}_{5} \mathrm{OH}+5 \% \mathrm{H}_{2} \mathrm{O}$ solution. Data were collected by the nanosizer

UV-VIS studies of this product are shown in Fig. 4. The spectra are similar for all the considered alcohols. The intensive bands are observed at 980 and below $400 \mathrm{~nm}$. The first one $(980 \mathrm{~nm})$ originates from $\mathrm{OH}$ groups linked to a metal atom and the second one (below $400 \mathrm{~nm}$ ) stems from aluminum oxide. Intensity of the latter is shifted towards lower wavelengths with increasing chain length in the molecule of alcohol.

Investigations of the particle sizes in the colloids were carried out with the nanosizer and the results are shown in Figs. 5, 6, and 7. In the methanol solutions, two typical sizes can be distinguished; a medium size of $230 \mathrm{~nm}$ for a majority and a large size of $470 \mathrm{~nm}$ for a minority of micelles (Fig. 5). The most homogeneous size with the average of $230 \mathrm{~nm}$ was obtained for ethanol solutions (Fig. 6). The micelles obtained in propanol have the largest spread of their sizes. In this case,

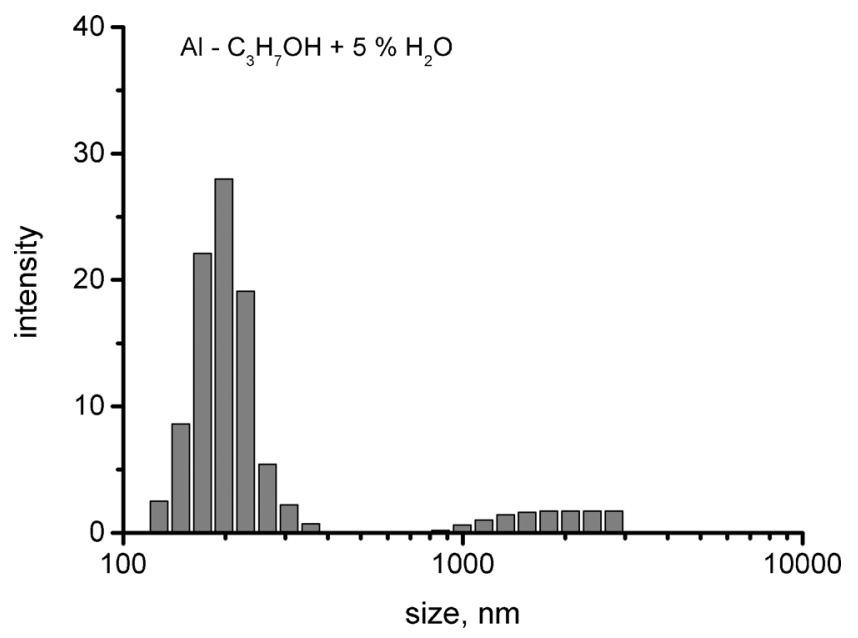

Fig. 7 Distribution of micelle size in the colloid obtained by a galvanostatic aluminum polarization in the $0.05-\mathrm{M} \mathrm{LiCl}-\mathrm{C}_{3} \mathrm{H}_{7} \mathrm{OH}+5 \% \mathrm{H}_{2} \mathrm{O}$ solution. Data were collected by the nanosizer

the smallest micelles, which are of considerable majority, have average sizes of $200 \mathrm{~nm}$, whereas a small quantity has a size larger than 1,000 nm (Fig. 7).

Particle sizes obtained from the nanosizer are much larger than those from TEM, which will be discussed further in the text. This is caused by the fact that both aluminum hydroxide and aluminum oxide particles are very active and can attach easily to hydrophile groups such as $\mathrm{OH}$. $\mathrm{OH}$ groups present at nanoparticle surfaces lead to an agglomeration by means of hydrogen bonds and hydroxyl bridges [20]. A second factor supporting the emergence of agglomerates is the nature of aluminum ions, which form $\left[\mathrm{Al}\left(\mathrm{H}_{2} \mathrm{O}\right)_{6}\right]^{3+}$ complexes in the presence of water. Particles of water in the complexes are replaced progressively by hydroxyl ions according to the following reaction [21]:

$\left[\mathrm{Al}\left(\mathrm{OH}_{2}\right)_{6}\right]^{3+} \rightarrow\left[\mathrm{Al}(\mathrm{OH})\left(\mathrm{OH}_{2}\right)_{5}\right]^{2+} \rightarrow\left[\mathrm{Al}(\mathrm{OH})_{2}\left(\mathrm{OH}_{2}\right)_{4}\right]^{+} \rightarrow\left[\mathrm{Al}(\mathrm{OH})_{3}\left(\mathrm{OH}_{2}\right)_{3}\right]$

These complexes undergo a condensation, what leads to a formation of polynuclear complexes [22, 23].

FTIR spectra for the colloids after the polarization are shown in Figs. 8, 9, and 10 together with corresponding spectra of initial solutions. The largest differences are observed for the methanol-based solutions. Characteristic bands are found at the same wave numbers as for methyl alcohol but their intensity is considerably larger. A broadening and increased intensity of the band at $660 \mathrm{~cm}^{-1}$ as compared to the initial solution is attributed to the presence of aluminum oxides [13, 21, 24]. The appearance of the broadened band at $1,030 \mathrm{~cm}^{-1}$ suggests the presence of the $\mathrm{Al}-\mathrm{OH}$ bond [25]. The increased band intensity at $1,110 \mathrm{~cm}^{-1}$ is related to the presence of methoxy groups. The broad band at 3,750-
$3,000 \mathrm{~cm}^{-1}$ originates from $\mathrm{OH}$ groups, which are adsorbed on surfaces of $\mathrm{Al}(\mathrm{OH})_{3}$ nanoparticles [20]. Such a broadening is also an effect of the aluminum ion nature, which forms $\left[\mathrm{Al}_{3}(\mathrm{OH})_{4}\left(\mathrm{OH}_{2}\right)_{10}\right]^{5+}$ complexes in a presence of water. Such complexes are a precursor to further condensation, which leads to a formation of $\left[\mathrm{Al}_{13} \mathrm{O}_{4}(\mathrm{OH})_{24}\left(\mathrm{OH}_{2}\right)_{12}\right]^{7+}$ polycations in acid environments and $\left[\mathrm{Al}_{4} \mathrm{O}(\mathrm{OH})_{10}\left(\mathrm{OH}_{2}\right)_{5}\right]^{0}$ in neutral environments $[22,23]$. Such an accumulation of $\mathrm{OH}$ groups in various configurations has to yield a broad band at the wavelength corresponding to $\mathrm{OH}$ group oscillations. The peak at $1,660 \mathrm{~cm}^{-1}$ originates from the oscillations in water molecules [21]. In the starting solutions, this peak is weakly visible because of low water content, which is $5 \%$ of the volume. During the polarization, alcohol is oxidized to water and 


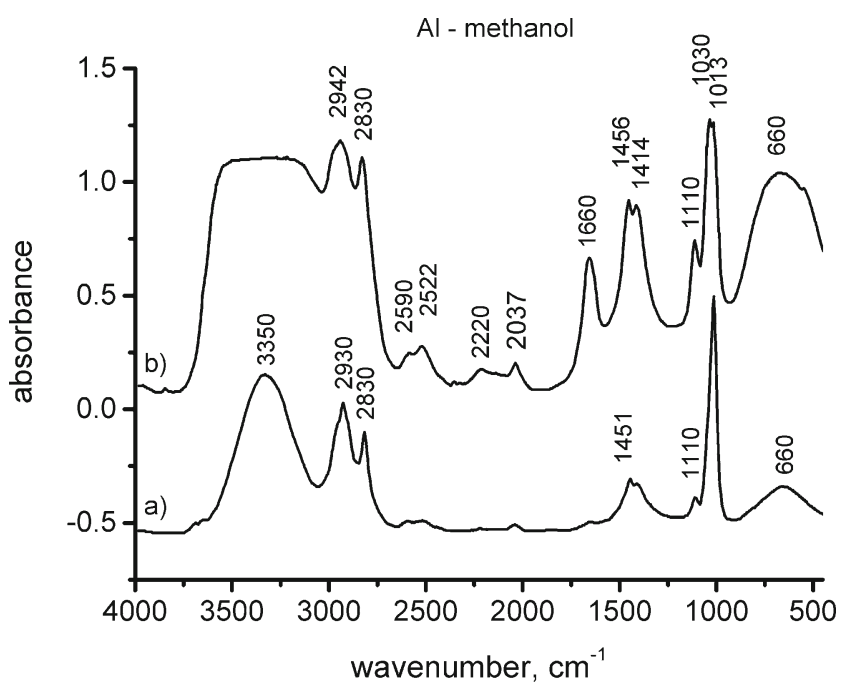

Fig. 8 FTIR studies of $\mathbf{a}$ initial solution and $\mathbf{b}$ colloid obtained in the galvanostatic polarization of aluminum in $0.05-\mathrm{M} \mathrm{LiCl}-\mathrm{CH}_{3} \mathrm{OH}+5 \%$ $\mathrm{H}_{2} \mathrm{O}$

carbon oxides and in consequence, the peak at $1,660 \mathrm{~cm}^{-1}$ grows. The bands from carbon monoxide (CO) and carbon dioxide $\left(\mathrm{CO}_{2}\right)$ are also visible in the colloid at wavenumbers equal to 2,037 [26] and 2,220 $\mathrm{cm}^{-1}$ [27], respectively. A broad band located between 2,300 and $3,500 \mathrm{~cm}^{-1}$ with a few peaks, e.g., near $2,500 \mathrm{~cm}^{-1}$ originates from stretching vibrations of $\mathrm{CH}$ and $\mathrm{OH}$ in carboxylic acids [28], which are formed in a partial oxygenation of alcohol. For the colloids obtained in ethanol and propanol, the bands related to the products of alcohol oxidation are much weaker.

FTIR studies on powders deposited from methanol, ethanol, and propanol solutions are presented in Fig. 11. The results indicate that the chemical composition of the obtained particles is similar for all the alcohols. Broad bands in the range of $400-800 \mathrm{~cm}^{-1}$ represent stretching vibrations of Al-O

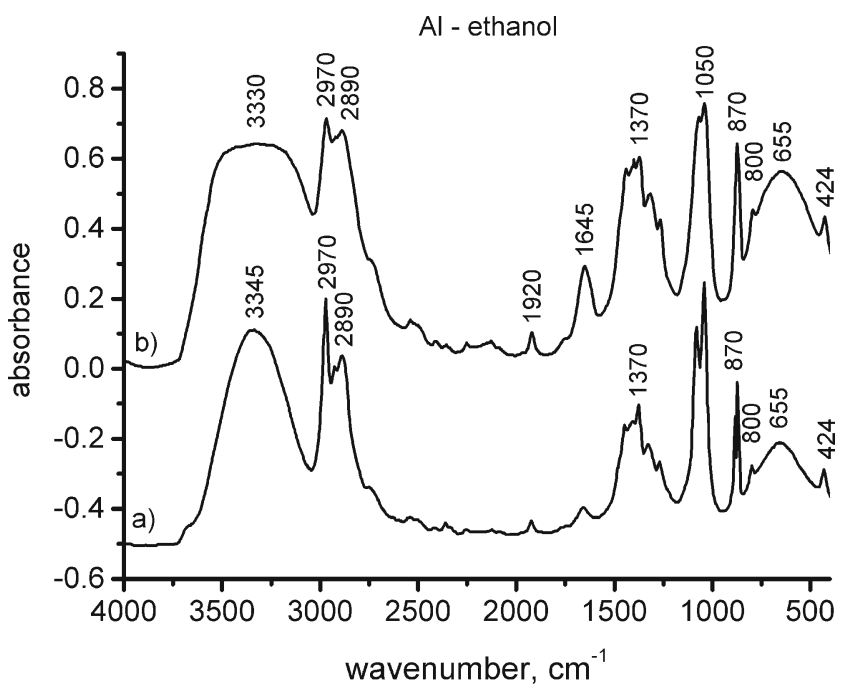

Fig. 9 FTIR studies of $\mathbf{a}$ initial solution and $\mathbf{b}$ colloid obtained in the galvanostatic polarization of aluminum in $0.05-\mathrm{M} \mathrm{LiCl}-\mathrm{C}_{2} \mathrm{H}_{5} \mathrm{OH}+5 \%$ $\mathrm{H}_{2} \mathrm{O}$

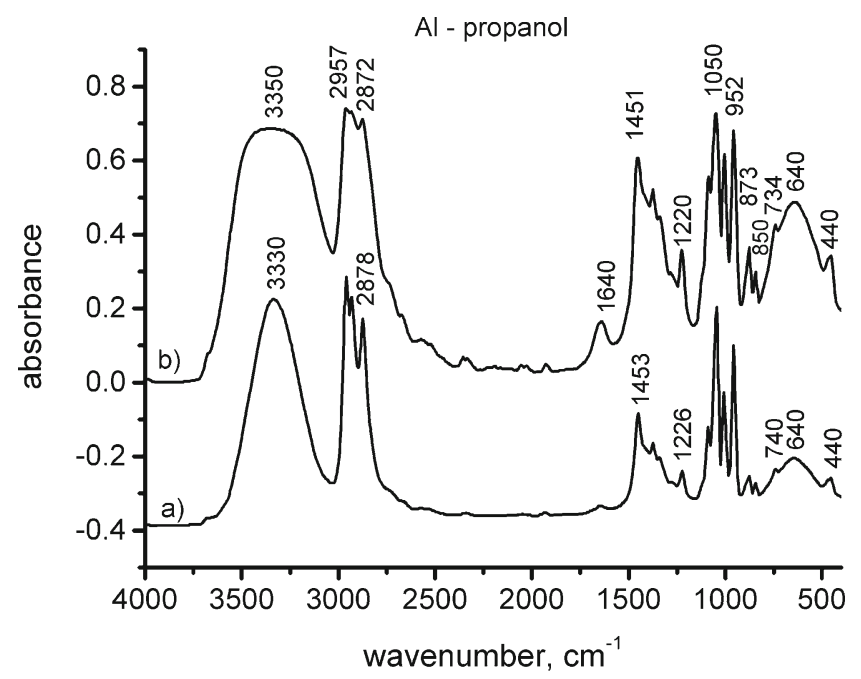

Fig. 10 FTIR studies of a initial solution and $\mathbf{b}$ colloid obtained in the galvanostatic polarization of aluminum in $0.05-\mathrm{M} \mathrm{LiCl}-\mathrm{C}_{3} \mathrm{H}_{7} \mathrm{OH}+5 \%$ $\mathrm{H}_{2} \mathrm{O}$

bonds for octahedral $\left(\mathrm{AlO}_{6}\right)$ and tetrahedral $\left(\mathrm{AlO}_{4}\right)$ coordination in ultra fine particles or amorphous structure of aluminum hydroxide. A broad band observed at 3,000-3,750 $\mathrm{cm}^{-1}$ originates from stretching vibrations of $\mathrm{O}-\mathrm{H}$ [24]. A band at $1,640 \mathrm{~cm}^{-1}$ is related to adsorbed water. More detailed discussion of the recorded FTIR bands was given before. The FTIR spectra are compatible with the presence of $\mathrm{Al}$ in oxides, hydroxides, and aluminates.

X-ray diffraction studies (Fig. 12) performed on the powders obtained with methanol and ethanol enabled the identification of crystalline phases in the powder. One can distinguish very broad peaks or humps from the mixture of $\mathrm{Li}_{2} \mathrm{Al}_{2} \mathrm{O}_{4} \mathrm{H}_{2} \mathrm{O}$ and $\mathrm{LiAl}_{2}(\mathrm{OH})_{7} 12 \mathrm{H}_{2} \mathrm{O}$ phases as well as sharp and narrow peaks from metallic aluminum. The broadened reflexes are the evidence of a small particle size and/or poorly crystallized

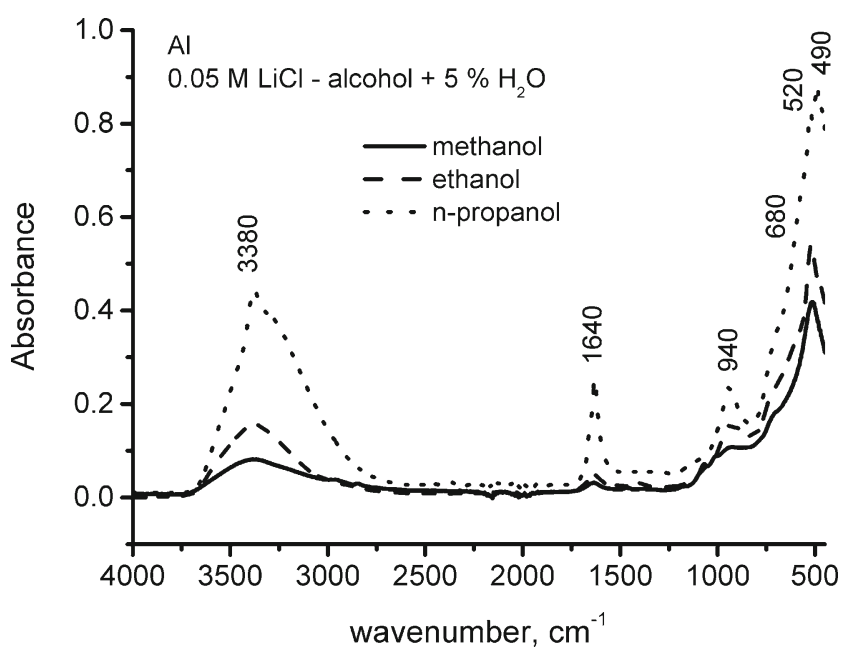

Fig. 11 FTIR studies of the powder obtained from Al polarization in $0.05-\mathrm{M} \mathrm{LiCl}$ solution based on different alcohols with $5 \%$ of water 


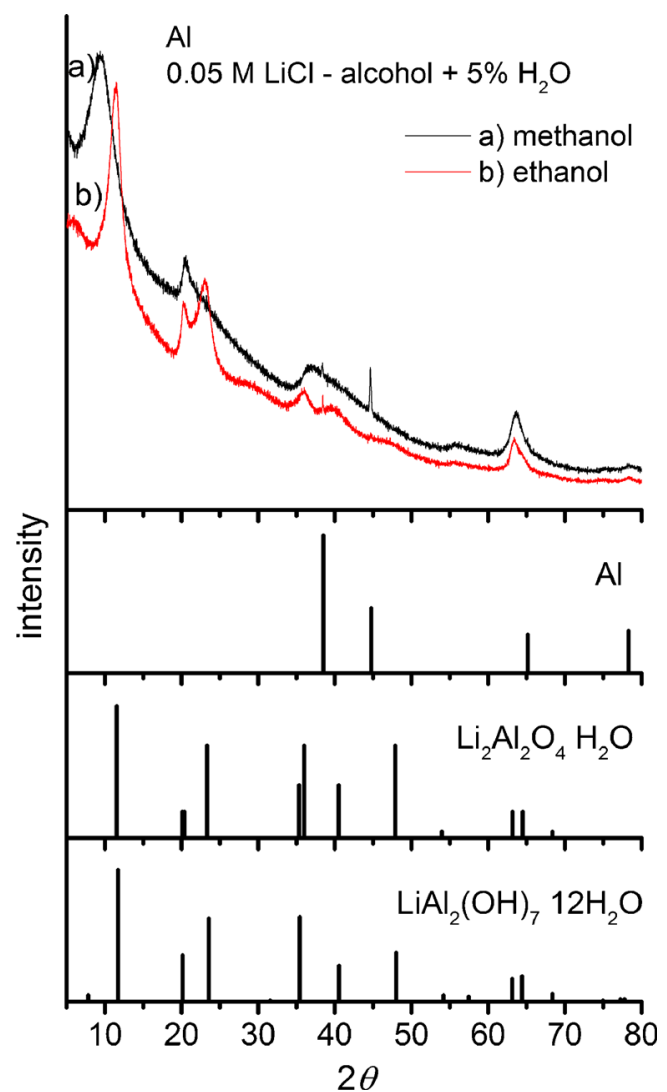

Fig. 12 X-ray diffraction patterns obtained with $\mathrm{Cu} \mathrm{K}$ line for the powders obtained in $0.05-\mathrm{M} \mathrm{LiCl}$ in methanol and ethanol solutions with $5 \%$ of water

phase, whereas metallic aluminum exhibiting sharp diffraction peaks forms large particles.

TEM images for the powders obtained in methanol solutions revealed that the deposit has a character of thin deformed membranes assembled in small aggregations (Fig. 13). The size of a single flake reaches $\sim 200 \mathrm{~nm}$ with the thickness of $\sim 15 \mathrm{~nm}$. High-resolution studies (Fig. 13b) indicates that the investigated powder has amorphous structure. The electron diffraction image consists of rings characteristic of amorphous matter. The investigations performed for the powders obtained in propanol solutions revealed that the deposit has a similar character to the one obtained in methanol solutions. The particles exhibit flake-like shapes with the size reaching $\sim 50 \mathrm{~nm}$ and a thickness of $5 \mathrm{~nm}$. The corresponding TEM images are qualitatively similar to those in Fig. 13 (not shown). High-resolution observations allowed to conclude that at least a part of the flakes is formed of a crystalline material. Electron diffraction (Fig. 14, Table 1) indicated the presence of very weak lines corresponding to interplanar distances of a pure aluminum with the background of large rings originating from amorphous matter.

The phase content from the electron diffraction seems not to be consistent with the XRD data. However, this discrepancy arises from the fact that the electron diffraction with TEM is a
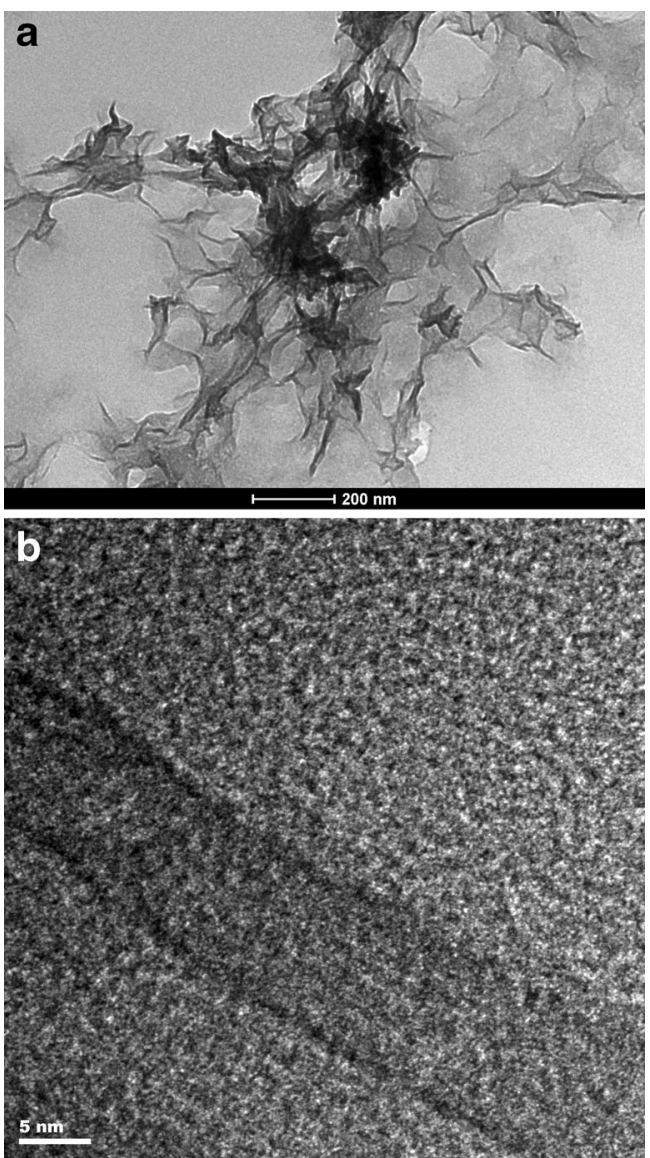

Fig. 13 Microstructure obtained by TEM in a bright field mode (a) and a high-resolution image (b) for the sample synthesized in $0.05-\mathrm{M} \mathrm{LiCl}-$ $\mathrm{CH}_{3} \mathrm{OH}+5 \% \mathrm{H}_{2} \mathrm{O}$ solution

local probe, while XRD examines a large area of the sample. If the results from XRD and TEM are combined, one can conclude that crystallographic phases of $\mathrm{Li}_{2} \mathrm{Al}_{2} \mathrm{O}_{4} \mathrm{H}_{2} \mathrm{O}$, $\mathrm{LiAl}_{2}(\mathrm{OH})_{7} 12 \mathrm{H}_{2} \mathrm{O}$, and $\mathrm{Al}$ are present together with a large amount of inorganic aluminum oxides and hydroxides.

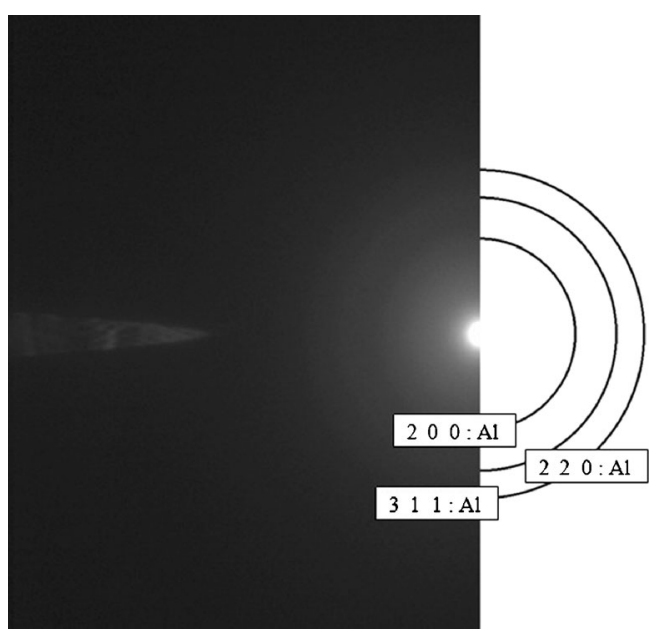

Fig. 14 Electron diffraction image obtained during the TEM studies for the powder obtained in the propanol solution. The rings denote maximal intensities 
Table 1 Interplanar distances determined for the electron diffraction image from Fig. 14 (powder) corresponding to the deposit from the propanol-based solution. Interplanar distances with Miller indices for aluminum are shown for comparison (Al)

\begin{tabular}{lll}
\hline Powder & $\mathrm{Al}$ & \\
\cline { 2 - 3 }$d(\AA)$ & $d(\AA)$ & $(\mathrm{hkl})$ \\
\hline 2.026 & 2.025 & $(200)$ \\
1.404 & 1.432 & $(220)$ \\
1.120 & 1.169 & $(222)$ \\
\hline
\end{tabular}

The interesting phenomenon is the appearance of metallic aluminum for the range of high anodic current density. It is assumed that zero-valent metals are a product of a disproportionation reaction during anodic process of metal dissolution in alcohols. The occurrence of such a reaction at high anodic potential is the important result.

\section{Conclusions}

We succeeded to obtain nanoparticles by anodic polarization of aluminum in $0.05-\mathrm{M} \mathrm{LiCl}-$ alcohol $+5 \% \mathrm{H}_{2} \mathrm{O}$. The chemical composition of the product does not depend considerably on alcohol. The synthesized nanoparticles are a mixture of poorly crystallized aluminates, amorphous oxides, and hydroxides as well as metallic aluminum. The morphology of the product is strongly influenced by the properties of $\mathrm{Al}_{2} \mathrm{O}_{3}$, $\mathrm{AlOOH}$, and $\mathrm{Al}(\mathrm{OH})_{3}$, which have a tendency to adsorb water and $\mathrm{OH}$ groups. This leads to a formation of agglomerates. The obtained nanoparticles have a morphology of membranes and flakes. They are $\sim 200$-nm large and $\sim 15$-nm thick for the methanol-based solution and $\sim 50$-nm large with $\sim 5$-nm thickness for the propanol-based solution.

Open Access This article is distributed under the terms of the Creative Commons Attribution License which permits any use, distribution, and reproduction in any medium, provided the original author(s) and the source are credited.

\section{References}

1. Darlington TK, Neigh AM, Spencer MT, Nguyen OT, Oldenburg SJ (2009) Nanoparticle characteristics affecting environmental fate and transport through soil. J Environ Toxicol Chem 28(6):1191-1199

2. Vučina-Vujović AJ, Janković IA, Milonjić SK, Nedeljkovic JM (2003) Influence of AlOOH nanoparticles on the oxidation of iodide by persulphate. Colloids Surf A 223:295-300

3. Zhang M, Gao B (2013) Removal of arsenic, methylene blue, and phosphate by biochar/AlOOH nanocomposite. Chem Eng J 226:286-292

4. Hou H, Zhu Y, Tang G, Hu Q (2012) Lamellar $\gamma$-AlOOH architectures: synthesis and application for the removal of $\mathrm{HCN}$. Mater Charact 68:33-41
5. Chen Q, Udomsangpetch C, Shen SC, Liu YC, Chen Z, Zeng XT (2009) The effect of AlOOH boehmite nanorods on mechanical property of hybrid composite coatings. Thin Solid Films 517:4871-4874

6. Ciubotariu AC, Benea L, Lakatos-Varsanyi M, Dragan V (2008) Electrochemical impedance spectroscopy and corrosion behaviour of $\mathrm{Al}_{2} \mathrm{O}_{3}-\mathrm{Ni}$ nanocomposite coatings. Electrochim Acta 53:4557-4563

7. Kim Y, Kim HS, Martin SW (2006) Synthesis and electrochemical characteristics of $\mathrm{Al}_{2} \mathrm{O}_{3}$-coated $\mathrm{LiNi}_{1 / 3} \mathrm{Co}_{1 / 3} \mathrm{Mn}_{1 / 3} \mathrm{O}_{2}$ cathode materials for lithium ion batteries. Electrochim Acta 52:1316-1322

8. Li Z, Su G, Gao D, Wang X, Li X (2004) Effect of $\mathrm{Al}_{2} \mathrm{O}_{3}$ nanoparticles on the electrochemical characteristics of P(VDF-HFP)-based polymer electrolyte. Electrochim Acta 49:4633-4639

9. He T, Xiang L, Zhu W, Zhu S(2008) $\mathrm{H}_{2} \mathrm{SO}_{4}$-assisted hydrothermal preparation of $\gamma-\mathrm{AlOOH}$ nanorods, Mater Lett 62:2939-2942

10. Tang Z, Liu YQ, Li GC, Hu XF, Liu CG (2012) Mater Res Bull 47:3177

11. Kim T, Lian JB, Ma JM, Duan XC, Zheng WJ (2010) Cryst Growth Des 10:2928

12. Li G, Liu Y, Liu D, Liu L, Liu C (2010) Synthesis of flower-like boehmite $(\mathrm{AlOOH})$ via a simple solvothermal process without surfactant. Mater Res Bull 45:1487-1491

13. Kong J, Chao B, Wang T, Yan Y (2012) Preparation of ultrafine spherical $\mathrm{AlOOH}$ and $\mathrm{Al}_{2} \mathrm{O}_{3}$ powders by aqueous precipitation method with mixed surfactants. Powder Technol 229:7-16

14. Wu X, Wang D, Hua Z, Gua G (2008) Synthesis of $\gamma$-AlOOH $(\gamma$ A12O3) self-encapsulated and hollow architectures. Mater Chem Phys 109:560-564

15. Starowicz M, Stypuła B (2008) Electrochemical synthesis of $\mathrm{ZnO}$ nanoparticles. Eur J Inorg Chem 6:869-872

16. Stypuła B, Banaś J, Starowicz M, Krawiec H, Bernasik A, Janas A (2006) Production of nanoparticles of copper compounds by anodic dissolution of copper in organic solvents. J Appl Electrochem 36:1407-1414

17. Starowicz M, Starowicz P, Żukrowski J, Przewoźnik J, Lemański A, Kapusta C, Banaś J (2011) Electrochemical synthesis of magnetic iron oxide nanoparticles with controlled size. J Nanoparticle Res 13: 7167-7176

18. Stypuła B, Starowicz M, Hajos M, Olejnik E (2011) Electrochemical synthesis of $\mathrm{ZnO}$ nanoparticles during anodic dissolution of zinc in alcohols solvents. Arch Metall Mater 56:287-292

19. Siewiorek A (2004) Doctoral thesis. AGH-University of Science and Technology, Krakow, Poland

20. Zhu L, Pu S, Lu F, Liu K, Zhu T, Li J, Li J (2012) Preparation of dispersed aluminum hydroxide nanoparticles via non-aqueous route and surface modification. Mater Chem Phys 135:979-984

21. Meher T, Basu AK, Ghatak S (2005) Physicochemical characteristics of alumina gel in hydroxy hydrogel and normal form. Ceram Int 31: 831-838

22. Mahé M, Reynders P, Demourgues A, Heintz JM (2007) Influence of a ceramic substrate on aqueous precipitation and structural evolution of alumina nano-crystalline coatings. J Am Ceram Soc 90:217-224

23. Henry M, Jolivet JP, Livage J (1992) Aqueous chemistry of metal cations: hydrolysis, condensation and complexation. Struct Bond 77:153-206

24. Du X, Wang Y, Su X, Li J (2009) Influences of $\mathrm{pH}$ value on the microstructure and phase transformation of aluminum hydroxide. Powder Technol 192:40-46

25. Hirani N, Chvedov D, Jones R (2007) Characterization of organic monolayers on the surface of aluminum in the process of thermal treatment. Thin Solid Films 516:310-315

26. Qiao B, Wang A, Yang X, Allard LF, Jiang Z, Cui Y, Liu J, Li J, Hang $\mathrm{T}$ (2011) Single-atom catalysis of $\mathrm{CO}$ oxidation using $\mathrm{Pt}_{1} / \mathrm{FeO}_{\mathrm{x}}$. Nat Chem 3:634-641

27. Liu Q, Mace A, Bacsik Z, Sun J, Laaksonen A, Hemin N (2010) NaKA sorbents with high $\mathrm{CO}_{2}$-over- $\mathrm{N}_{2}$ selectivity and high capacity to adsorb $\mathrm{CO}_{2}$. Chem Commun 46:4502-4504

28. Gadermann M, Vollmar D, Signorell R (2007) Infrared spectroscopy of acetic acid and formic acid aerosols: pure and compound acid/ice particles. Phys Chem Chem Phys 9:4535-4544 